\title{
How Many Deaths Can Be Prevented by Newborn Screening for Congenital Adrenal Hyperplasia?
}

\author{
Scott D. Grosse ${ }^{a}$ Guy Van Vliet ${ }^{b}$ \\ a National Center on Birth Defects and Developmental Disabilities, Centers for Disease Control and Prevention, \\ Atlanta Ga., USA; ${ }^{b}$ Department of Pediatrics, University of Montreal, and Endocrinology Service and Research Center, \\ Sainte-Justine Hospital, Montreal, Que., Canada
}

\section{Key Words}

Congenital adrenal hyperplasia, screening $\cdot$ Neonatal screening $\cdot$ Mortality, newborns $\cdot$ Evidence-based medicine $\cdot$ Cost-effectiveness analysis

\begin{abstract}
Background/Aims: Congenital adrenal hyperplasia (CAH) is increasingly being included in newborn screening programs. Screening can prevent neonatal mortality in children with salt-wasting $\mathrm{CAH}$, but the number of deaths prevented is not known. Cost-effectiveness analyses of screening require estimates of the probability of mortality in CAH. Methods: We reviewed the literature to identify cohort studies of children with $\mathrm{CAH}$ ascertained clinically in the absence of screening. We abstracted the numbers of infant deaths attributable to $\mathrm{CAH}$. We also addressed sex ratios among children with clinically detected $\mathrm{CAH}$ and the contribution of ascertainment bias to unbalanced ratios. Results: The evidence suggests a probability of infant death due to adrenal crises in salt-wasting CAH of $4 \%$ or less in contemporary advanced economies without screening for $\mathrm{CAH}$. This is lower than previous estimates, although the rate of mortality could
\end{abstract}

Disclaimer: The findings and conclusions in this report are those of the authors and do not necessarily represent the views of the Centers for Disease Control and Prevention.

\section{KARGER}

Fax +41613061234 E-Mail karger@karger.ch www.karger.com
(C) 2007 S. Karger AG, Basel

0301-0163/07/0676-0284\$23.50/0

Accessible online at:

www.karger.com/hre be considerably higher in populations with limited clinical awareness or access. Conclusion: Although screening for $\mathrm{CAH}$ is conducted in a number of countries, further research is still needed to provide reliable estimates on the numbers of prevented deaths, along with evidence-based assessments of the potential benefits, harms, and costs of screening.

Copyright $\odot 2007$ S. Karger AG, Basel

\section{Introduction}

Classical congenital adrenal hyperplasia $(\mathrm{CAH})$ caused by deficiency of the 21-hydroxylase enzyme is a potentially lethal endocrine disorder that occurs in approximately 1 in 15,000 children born in Europe and North America $[1,2]$. It is an autosomal recessive disorder caused by mutations in the CYP21 gene (OMIM 201910) that result in insufficient synthesis of cortisol and aldosterone and excessive synthesis of androgens. The disorder takes two forms, salt-wasting (SW-CAH) and simple virilizing (SV-CAH), with SW-CAH comprising the bulk (66-75\%) of cases. Female children with both types are subject to in utero virilization of the genitalia, and children with SW-CAH are also subject to salt-losing episodes. These can manifest as early as the first week of life and become life-threatening.

National Center on Birth Defects and Developmental Disabilities

Centers for Disease Control and Prevention

1600 Clifton Road, MS E87, Atlanta, GA 30333 (USA)

Tel. +1 404498 3074, Fax +1 404498 3070, E-Mail sgrosse@cdc.gov 
Screening of newborn infants for CAH was developed in the late 1970s using a radioimmunoassay for 17-hydroxyprogesterone (17-OHP) in dried blood spots collected on filter paper cards from infants soon after birth $[2,3]$. Since then, newborn screening for $\mathrm{CAH}$ has become adopted in most parts of the United States and in a number of other countries, including New Zealand, Japan, Israel, Sweden, Switzerland, France, Austria, and the Netherlands [4]. As of June 2006, CAH has also been screened for in selected regions of Canada, Spain, Germany, and Italy. The primary goal of screening for $\mathrm{CAH}$ is to detect severe SW-CAH in order to prevent salt-losing crises by presymptomatic treatment. Shortening the period of incorrect sex assignment in affected females and other consequences of virilization among both males and females are additional benefits $[2,4]$.

The lack of universal acceptance of newborn screening for $\mathrm{CAH}$ reflects the low incidence of the disorder, varying perceptions of the public health impact of the disorder, and uncertainty about the benefits of early detection in terms of increased diagnosis and reduced mortality [4-12]. We present a review of the epidemiologic literature on the frequency of mortality due to SW-CAH in order to inform policy decisions on newborn screening for $\mathrm{CAH}$. Other benefits and risks of screening for $\mathrm{CAH}$ would also need to be addressed in an evidence-based review of $\mathrm{CAH}$ newborn screening.

\section{Methods}

This article is an extension of a review undertaken for a costeffectiveness analysis of newborn screening for CAH in the United States [13]. The goal was to identify estimates of mortality due to $\mathrm{CAH}$ in populations of predominantly European origin with and without newborn screening for the disorder. The initial search strategy identified English-language articles in Medline published from 1980 to 2004 with the keywords 'congenital adrenal hyperplasia' and either 'newborn screening' or 'mortality'. We extended the search strategy to identify additional populationbased research studies through use of the 'related articles' feature in Medline to scan articles that were potentially similar to studies already identified for inclusion. In addition, we reviewed lists of references to identify additional articles published in English or French from 1980 through June 2006. We defined populationbased studies as assessments that used multiple methods of case ascertainment to identify known cases of CAH in a defined geographic area. Reports based on clinical case series were considered as background information.

Articles were evaluated for biases. Two indicators were used to assess the under-ascertainment caused by early, unrecognized deaths. One is the sex ratio among cases of SW-CAH, since most cases of unrecognized mortality occur among males. The other is the rate of SW-CAH in comparison with screening in the same population, either in adjoining districts or in a different time period. If SW-CAH in an unscreened cohort is identified with the same frequency and with an approximately equal sex ratio, the extent of ascertainment bias is likely to be minimal. Because of small numbers, the sex ratio in an individual study could by chance show an excess of either males or females.

Another potential bias in observational studies of screened and unscreened cohorts is differences in standards of care. This is particularly a problem for historical comparisons, because improvements over time in medical care can result in reduced rates of mortality, independent of age of diagnosis. Consequently, using an unscreened cohort as an historical control for evaluating the effectiveness of screening is likely to overstate any reduction of mortality due to screening. Regional comparisons can also be affected by differences in care within the same country.

\section{Results}

\section{CAH-Related Mortality without Screening}

The literature on the frequency of mortality in children with $\mathrm{CAH}$ in the absence of screening is characterized by diverse opinions and an absence of evidence-based reviews [8]. Many experts have declined to speculate on the frequency of mortality [2, 4-12]. Although one group of endocrinology experts suggested that $20-40 \%$ of babies with classical CAH would die without screening [1], other estimates have been lower. The American Academy of Pediatrics in 1996 stated, 'Life-threatening adrenal crises in the newborn period' are associated with ' $9 \%$ mortality', although no source was cited [14]. This appeared to be an estimate of the case-fatality rate among children with adrenal crises. Recently, an expert group convened by the American College of Medical Genetics stated that mortality in classical CAH as a whole is $9 \%$ [15].

Cost-effectiveness analyses of screening for $\mathrm{CAH}$ require numerical estimates of the frequency of death from salt-losing crises in the absence of screening. One US cost-effectiveness study assumed $10 \%$ mortality from salt-losing crises in a cohort of children with classical $\mathrm{CAH}$, citing 'expert opinion' [16], which implies 13\% mortality for the subset of SW-CAH cases. In Finland, a recent cost-effectiveness analysis projected that $\mathrm{CAH}$ caused one death in each 110,000-170,000 births without screening [17]. The analysis implicitly assumed 16-25\% mortality among children with SW-CAH [17], citing a Finnish study [18].

\section{Sex Ratios}

Because CAH is an autosomal recessive disorder, the sex ratio at birth is approximately equal [19]. It is commonly stated that in the absence of screening many more 
females than males are detected with $\mathrm{CAH}$ and that this constitutes evidence of unrecognized mortality among males [19-23]. However, an unequal sex ratio could also result from differential case ascertainment because females are typically diagnosed on the basis of ambiguous genitalia [9]. Males with mild phenotypes, even among those with SW-CAH, might not be detected until growth problems are observed in later childhood or as the result of detection of a younger affected sibling [24].

Case series from hospitals have often indicated an imbalance in sex ratios among children diagnosed with $\mathrm{CAH}$ in the absence of screening $[20,22,25]$. This is particularly the case for hospitals to whom children born elsewhere are referred for correction of ambiguous genitalia. At one such hospital in England, the sex ratio was 2.9 females per male, compared with a female-male ratio of 1.2 at four other hospitals [25]. Because of referral bias, reports from individual hospitals can be unreliable sources of information.

Not all hospitals report an excess of females with CAH. At the Birmingham Children's Hospital in England, there were 16 females and 14 males among children diagnosed with SW-CAH during 1959-1969, and 19 of each among children born during 1970-1985 [26]. Between 1969 and 1994, at the Royal Children's Hospital in Victoria, Australia, 42 male and 41 female children were diagnosed with classical $\mathrm{CAH}$ based on symptomatic presentation, excluding 5 females referred for genital surgery [6]. At the Sainte-Justine Hospital in Montreal, Canada, 53 SWCAH cases were diagnosed during 1981-2001, with 27 females and 26 males [24]. The cases represented about half of all affected births in Quebec during this period [27].

Most population-based cohort studies report comparable numbers of males and females diagnosed with SWCAH. In Switzerland, a ratio of 1.10 females per male was observed among children with classical CAH born during 1960-1974, but no information was specifically presented for SW-CAH [28]. A surveillance study in Scotland identified 5 females and 10 males with classical CAH during 1979-1984 [29]. Among 5 population-based studies from Western Europe and North America of unscreened birth cohorts which reported information specific to children with SW-CAH, only one had an excess of males and that difference could have been due to chance. The ratio of females to males was 1.50 among 20 children with SW-CAH in two US states, which was not significantly different from unity [30]. In the remaining 4 studies, the female to male ratio in children with SW$\mathrm{CAH}$ was 1.00 in Italy [31], 0.94 in Sweden [32], 0.91 in southwestern England [33], and 0.70 in the Netherlands [34]. In 5 countries in Middle Europe, the sex ratio among 313 children with SW-CAH detected during 1969-1998 was reported to be 1.13 [35]. However, comprehensive surveillance in one of those countries, Hungary, revealed that the sex ratio among 120 children detected with SWCAH during 1978-1998 was virtually equal, 1.03 [36]. An implication of this finding is that 'missing' males with SW-CAH are not necessarily dead; many are likely alive but undiagnosed in the absence of systematic testing of children with clinical signs consistent with $\mathrm{CAH}$.

We identified one quasi-population-based assessment of CAH cases in Europe. A cross-sectional study of 108 individuals of all ages with classical CAH treated at 21 academic and referral hospitals in Finland during 19801995 reported an overall female-to-male ratio of 1.34 [18]. Approximately half of the sample consisted of adults. An analysis of a subset that were genotyped found that among those with either complete or severe CYP21 mutations associated with salt-losing crises in infancy, there were 16 males and 15 females [37].

\section{Cohort Death Rates in Recognized CAH}

The reported number of recognized deaths due to saltlosing crises in $\mathrm{CAH}$ is likely to decline with improved standards of clinical awareness and practice. Studies that have examined time trends have reported lower mortality rates in more recent birth cohorts. For instance, in Hungary, it was reported that the infant mortality rate due to all causes among children diagnosed with classical CAH during the period $1969-1998$ was $11.3 \%$ as a whole, but this figure masks an $80 \%$ decline from $22.2 \%$ during the period 1969-1983, when steroid treatment was incomplete, to $4.5 \%$ during the period 1983-1998 [35]. Among infants referred with SW-CAH to Birmingham Children's Hospital in England, there were 2 deaths among 30 infants born during the period 1958-1969 and no deaths among 38 infants born during the period 19701985 [26]. Similarly, two deaths due to salt-losing crises were identified in a retrospective series of 63 infants born in southwestern England during 1968-1988, in addition to 2 deaths that might have been related to $\mathrm{CAH}$, but none of the deaths from salt-losing crises occurred after 1975 [33].

Three population-based studies have reported complete or near-complete case ascertainment of SW-CAH in birth cohorts without newborn screening (table 1). First, the prevalence of clinically detected CAH in Sweden was 1:11,500 during the period 1969-1986 before screening for $\mathrm{CAH}$ was introduced [32]. Of 148 children 
with classical CAH, 93 (63\%) had clinical salt loss, for a very conservative estimate of SW-CAH prevalence of $1: 18,600$ [32]. After the introduction of screening for $\mathrm{CAH}$, the prevalence of CAH during 1989-1994 was somewhat higher, 1:9,800, although not significantly so [38]. The authors noted that screening resulted in the detection of milder cases of $\mathrm{CAH}$ than during the earlier period, which apparently accounted for the greater prevalence [38]. Among 73 children with $\mathrm{CAH}$, the number classified with SW-CAH on biochemical grounds was 56 $(80 \%)$, for a prevalence of $1: 12,800$. However, the method of classifying SW-CAH in this study was not comparable with the earlier study, which was based on observation of a salt-losing episode before 3 months of age. Given the similarity in overall prevalence of classical CAH, and the milder spectrum observed in the latter period, if the same criteria had been used in both periods the diagnosed prevalence of SW-CAH would probably have been comparable. Among 93 infants with SW-CAH born during 1969-1986, 2 infant deaths were recorded, a 2.2\% mortality rate [32]. No deaths were reported among children identified with CAH through screening during 19891994, although this could reflect small numbers as well as changes in clinical care.

In the United States, data on clinically detected $\mathrm{CAH}$ cases among children born in two adjacent states (Arkansas and Oklahoma) during the period 1989-1994 were obtained through a survey of all pediatric endocrinologists in the two states [30]. The study identified 20 cases of SW-CAH among 400,118 births, with no deaths reported [30]. The frequency of SW-CAH cases detected, $1: 20,000$, was slightly higher than that detected by newborn screening in the neighboring state of Texas during the same period, 1:21,800 [39], and the sex ratio was not statistically significantly different from unity. The same case definition was used as in the Texas study, and all charts were reviewed for consistency with the case definition. A limitation was that sources of data other than pediatric endocrinologists were not consulted. Another, more serious limitation is that because of the small numbers involved, just 12 females and 8 males detected with $\mathrm{SW}-\mathrm{CAH}$, it is impossible to determine whether the smaller number of males observed was due to chance or to one or more unrecognized deaths among males.

In the Netherlands, during the period 1998-1999, 17 infants were diagnosed with SW-CAH in 8 provinces without screening for $\mathrm{CAH}$ and 15 were diagnosed in 4 provinces with pilot screening. The prevalence of $\mathrm{CAH}$ was identical in the two groups of provinces, 1:11,800 births, and the sex ratio was not significantly different from unity in the areas without screening [34]. No infant death was recorded among infants diagnosed with SWCAH in either screened or unscreened cohorts [34].

One other study reported long-term mortality among a group of 54 unscreened individuals of all ages with SWCAH treated at major hospitals in Finland during 19801995 [18]. Two deaths due to cortisol deficiency occurred in the first 12 months of life and 2 additional deaths were recorded at 23 months and 11 years [18]. One death at 2 weeks of life was a postmortem diagnosis, and the other three deaths occurred despite treatment for CAH. These data appear to suggest that $3.7 \%$ of children with recognized SW-CAH died in infancy, and a total of $7.4 \%$ died in childhood.

To sum up, overall recognized infant mortality in SW$\mathrm{CAH}$ in unscreened populations has been reported to vary from 0 to $4 \%$ in populations with high standards of clinical awareness and care for CAH. The two studies with no deaths reported $[30,34]$ did not yield precise estimates because of small numbers. The study from Sweden [32], which had prevalence rates consistent with subsequent screening data and roughly equal numbers of male and female SW-CAH cases, had a death rate of $2.2 \%$. Pooling the three studies with defined birth cohorts [30, 32,34 , the mean mortality rate was $1.5 \%$ (2 of 133 ; table 1). The $95 \%$ binomial confidence interval for this estimate is $0.2-5.3 \%$. This is likely an underestimate of mortality in SW-CAH because of unrecognized deaths. If 1 death due to SW-CAH was missed in any of the studies, the point estimate would have been $2.2 \%$, with a $95 \%$ confidence interval of $0.5-6.4 \%$.

The conservative estimate of $1.5 \%$ recognized mortality in population-based birth cohort studies is similar to a 1977 estimate of $1.5 \%$ mortality following diagnosis of SW-CAH [40] cited by Brosnan et al. [30]. Estimates of recognized mortality in SW-CAH from hospital-based studies with balanced sex ratios among diagnosed cases have ranged from 1.9 to $3.1 \%$. The death rate associated with adrenal crises in Montreal, Canada, was reported to be $1(1.9 \%)$ of 54 children, with the 1 infant death diagnosed at autopsy [27]. In Victoria, Australia, there were 2 (2.2\%) deaths potentially due to adrenal crises that occurred at 3-5 years among 89 children diagnosed with either SW-CAH or SV-CAH [6]. In Birmingham, there were 2 (3.1\%) deaths among 65 children with SW-CAH born during 1958-1985, both of whom died in infancy [26].

Not all deaths due to CAH occur during infancy [35]. In Finland, 2 deaths from cortisol deficiency during the period 1980-1995 occurred among children with diagnosed SW-CAH following infancy, at 23 months and 11 
Table 1. Population-based studies of CAH mortality comparing screened and unscreened cohorts

\begin{tabular}{|c|c|c|c|c|c|c|c|c|c|}
\hline \multirow[t]{2}{*}{ Study } & \multirow[t]{2}{*}{ Country } & \multirow[t]{2}{*}{ Screening } & \multirow[t]{2}{*}{ Birth years } & \multirow[t]{2}{*}{ Births } & \multirow[t]{2}{*}{ SW-CAH } & \multirow{2}{*}{$\begin{array}{l}\text { Prevalence } \\
\text { SW-CAH }\end{array}$} & \multirow{2}{*}{$\begin{array}{l}\text { Female-male } \\
\text { ratio }\end{array}$} & \multicolumn{2}{|c|}{ Deaths } \\
\hline & & & & & & & & $\mathrm{n}$ & $\%$ \\
\hline $\begin{array}{l}\text { Thilen and Larson } \\
\text { [32], } 1990\end{array}$ & Sweden & no & 1969-1986 & $1,727,928$ & 93 & $1: 18,600^{\mathrm{a}}$ & 0.94 & 2 & 2.2 \\
\hline $\begin{array}{l}\text { Thilen et al. } \\
\text { [38], } 1998\end{array}$ & & yes & 1989-1994 & 646,800 & 56 & $1: 12,800^{\mathrm{a}}$ & 1.24 & 0 & 0 \\
\hline \multirow{2}{*}{$\begin{array}{l}\text { Van der Kamp } \\
\text { et al. [34], } 2001\end{array}$} & \multirow[t]{2}{*}{ Netherlands } & no & 1998-1999 & 223,307 & 17 & $1: 13,100$ & 0.70 & 0 & 0 \\
\hline & & yes & 1998-1999 & 176,684 & 13 & $1: 13,600$ & 1.17 & 0 & 0 \\
\hline \multirow{4}{*}{$\begin{array}{l}\text { Brosnan et al. } \\
\text { [30], } 1999\end{array}$} & \multirow[t]{2}{*}{ United States } & no & 1989-1994 & 400,118 & 20 & $1: 20,000$ & 1.50 & 0 & 0 \\
\hline & & yes & 1989-1994 & $1,613,378$ & 74 & $1: 21,800$ & 0.68 & 1 & 1.4 \\
\hline & \multirow[t]{2}{*}{ Pooled } & no & & $2,351,353$ & 130 & $1: 18,100$ & 1.06 & 2 & 1.5 \\
\hline & & yes & & $2,436,862$ & 143 & $1: 17,500$ & 0.91 & 1 & 0.7 \\
\hline
\end{tabular}

a The two studies from Sweden used different criteria for SW-CAH, with a much stricter criterion used in the earlier study. The overall prevalence of classical CAH was not significantly different.

years, respectively [18]. Because cases of SW-CAH are usually detected clinically and treated before 6 months of age $[4,5]$, salt-losing deaths occurring after infancy probably reflect suboptimal management rather than delayed diagnosis. A study in England reported such deaths only among female children 1-4 years of age of South Asian ethnicity [25]. One newborn screening follow-up study reported 2 deaths in children at ages 13 months and 2 years who had been diagnosed with SW-CAH but were not under the care of pediatric endocrinologists [41].

\section{Prevention of CAH-Related Mortality with Screening}

The first step in evaluating a screening test is assessing specificity and sensitivity. Studies have reported that all children with severe SW-CAH are detected by analysis of 17-OHP levels on dried blood spot specimens, but up to one third of cases of SV-CAH are missed by analysis of a single specimen collected soon after birth $[42,43]$. Most cases of SV-CAH can be detected on analysis of a second specimen [39]. Treatment of the mother with dexamethasone before birth is a cause of false-negative 17-OHP screen [44].

The specificity of 17-OHP screening is limited because most children who screen positive for $\mathrm{CAH}$ based on a single-tier 17-OHP screen, especially premature infants and those with a stress challenge, do not actually have $\mathrm{CAH}$. In the past, up to 200 children in the United States had an abnormal 17-OHP screening result reported for each child who was ultimately diagnosed with CAH [45]. More recently, 8,151 infants were reported to screen pos- itive for CAH in the United States during 2003; of just over 2 million screened, only 99 , or $1.2 \%$, were diagnosed with some form of CAH [46]. In eastern Switzerland, a second filter paper card is requested for borderline 17OHP values adjusted for birth weight or gestational age. Of those with clearly elevated 17-OHP values on the first or second sample, $50 \%$ were confirmed by endocrinological examination to have $\mathrm{CAH}$ [47]. Methods are being evaluated to improve specificity through the addition of second-tier screens on the initial dried blood spot specimen using mutation analysis or tandem mass spectrometry $[48,49]$.

Many children with classical CAH are recognized or under clinical suspicion prior to the reporting of screening results. Studies report that $40-70 \%$ of children with SW-CAH screened at birth were first identified by screening $[38,39,47,50]$. A review reported that $68 \%$ of newborns with $\mathrm{CAH}$ were first identified by screening, but no distinction was made between SW-CAH and SV-CAH [19]. Early recognition, prior to an adrenal crisis, depends on the timeliness of reporting results $[1,9,14,19]$. The average age at which newborn screening results were reported was 11 days in two studies $[39,50]$ and 8 days in another [38].

The degree of effectiveness of newborn screening for $\mathrm{CAH}$ in reducing mortality from salt-losing crises is not well established, because few long-term follow-up studies of screened cohorts of children detected with CAH have been reported. In two studies, no CAH-related deaths were reported in a total of 69 screened infants with SW- 
CAH in Sweden [38] and the Netherlands [34]. In a third study, 1 death associated with a salt-losing crisis was reported among 74 infants detected with SW-CAH by screening in Texas [39]. Pooling the results from those 3 studies, the $\mathrm{CAH}$-specific mortality rate is $0.7 \%$ (table 1 ). One other study in France tracked 78 children diagnosed with SW-CAH through screening during 1985-1994 [41]. Of 5 deaths observed in this cohort, 2 were potentially attributable to $\mathrm{CAH}$ but a conclusive determination was not made.

\section{Discussion}

Unbalanced sex ratios in SW-CAH assessed at the population level can be an indicator of excess mortality among males, particularly in developing countries. For example, two population-based studies from the Middle East reported high ratios of females to males among SW$\mathrm{CAH}$ cases that suggest substantial unrecognized mortality $[51,52]$. On the other hand, in advanced economies, similar numbers of males and females are typically detected with SW-CAH at the population level, not only in Europe and North America but in countries like Singapore [53].

It is often reported that newborn screening increases the rate of detection of classical CAH $[4,19]$. On the other hand, it is only the frequency of detection of SW-CAH that is relevant to the potential prevention of mortality from salt-losing crises. Although certain studies comparing screened and unscreened cohorts report a lower prevalence of SW-CAH with clinical detection than newborn screening [31], other studies do not [30, 32, 34, 38, 39].

The number of infant deaths potentially preventable by newborn screening for $\mathrm{CAH}$ can be conservatively estimated on the basis of estimates of CAH-related deaths in unscreened cohorts. Population-based studies in highincome countries have reported SW-CAH mortality rates during infancy from 0 to $4 \%[30,32,34]$. The American Academy of Pediatrics [54] recently cited a Hungarian study [35] as reporting an average mortality rate of $11.3 \%$ among infants with SW-CAH. However, the infant mortality rate from 1984-1998 was much lower, approximately $4.5 \%$ [35].

Because of unrecognized deaths, the true mortality rate in infants with SW-CAH in contemporary industrialized countries without 17-OHP screening could be higher than $4 \%$. One way to ascertain such deaths in cohorts not screened for $\mathrm{CAH}$ at birth is to retrieve stored dried blood spot filter paper cards for children who died in infancy or early childhood and test for the presence of $\mathrm{CAH}$, including analysis of CYP21 mutations specific for SW-CAH.

We did not address other potential benefits of newborn screening for CAH [21]. For example, it has been suggested that early detection and treatment could potentially normalize linear growth and adult height, which are altered in both classical CAH and non-classical 21hydroxylase deficiency [55]. Although hormone replacement therapy and early diagnosis have been linked to increased adult height, this has not yet been established as a benefit of earlier detection [56]. Whether early detection of non-classical CAH is a benefit or an unwanted outcome of screening for classical CAH remains a matter of opinion.

The cost-effectiveness of screening for CAH is not well established, although the incremental cost per infant screened, which is reported to be approximately USD 5 [13] or EUR 5 [17], is in line with other newborn screening tests $[4,8,16,23,57]$. The primary driver of cost-effectiveness is the probability of death in SW-CAH. One analysis of screening for $\mathrm{CAH}$ in the United States assumed a mortality of $13 \%$ in SW-CAH and calculated a cost of USD 20,000 per life-year saved [16]. In contrast, a study which conservatively assumed a mortality of $4 \%$ or less projected a ratio of more than USD 100,000 per lifeyear saved [13]. Because outcomes other than averted deaths and hospitalizations were not considered, these analyses are necessarily incomplete.

More research is needed to quantify other outcomes of early detection, which should be taken into account in screening policy decisions. Policy makers should weigh the balance of benefits, costs, and potential harms incurred by screening, including parental anxiety from false-positive screening results and unnecessary treatment of children who might be incorrectly diagnosed with SW-CAH. It appears timely for a systematic evidence-based review of all aspects of screening for $\mathrm{CAH}$ to be conducted to inform screening policy decisions in countries which do not currently screen for CAH.

\section{Acknowledgements}

Byung-Kwang Yoo contributed to the research underlying this article. We appreciate the helpful comments from the two reviewers.

Horm Res 2007;67:284-291 


\section{References}

-1 Pang SY, Wallace MA, Hofman L, Thuline HC, Dorche C, Lyon IC, Dobbins RH, Kling S, Fujieda K, Suwa S: Worldwide experience in newborn screening for classical congenital adrenal hyperplasia due to 21-hydroxylase deficiency. Pediatrics 1988;81:866-874.

-2 Therrell BL: Newborn screening for congenital adrenal hyperplasia. Endocrinol Metab Clin North Am 2001;30:15-30.

$\checkmark 3$ Pang S, Hotchkiss J, Drash AL, Levine LS, New MI: Microfilter paper method for 17 alpha-hydroxyprogesterone radioimmunoassay: its application for rapid screening for congenital adrenal hyperplasia. J Clin Endocrinol Metab 1977;45:1003-1008.

$\checkmark 4$ Honour JW, Torresani T: Evaluation of neonatal screening for congenital adrenal hyperplasia. Horm Res 2001;55:206-211.

$\checkmark 5$ Virdi NK, Rayner PH, Rudd BT, Green A: Should we screen for congenital adrenal hyperplasia? A review of 117 cases. Arch Dis Child 1987;62:659-662.

6 Lim YJ, Batch JA, Warne GL: Adrenal 21-hydroxylase deficiency in childhood: 25 years' experience. J Paediatr Child Health 1995;31: 222-227.

7 Migeon CJ, Donohoue PA: Adrenal disorders; in Kappy MS, Blizzard RM, Migeon CJ (eds): The Diagnosis and Treatment of Endocrine Disorders in Childhood and Adolescence. Springfield, Thomas, 1994, pp 717856.

$>8$ Brosnan CA, Brosnan PG: Methodological issues in newborn screening evaluation with special reference to congenital adrenal hyperplasia. J Pediatr Endocrinol Metab 2000; 13:1555-1562.

9 Van Vliet G: Neonatal endocrinopathies: should we change the screening methods? Ital J Pediatr 2005;31:209-212.

10 Donahue PA, Parker KL, Migeon CJ: Congenital adrenal hyperplasia; in Scriver CR, Beaudet AL, Sly WS, Valle D (eds). The Metabolic and Molecular Bases of Inherited Disease. New York, McGraw-Hill, 2001, pp 4077-4115.

11 Pollitt RJ, Green A, McCabe CJ, Booth A, Cooper NJ, Leonard JV, Nicholl J, Nicholson P, Tunaley JR, Virdi NK: Newborn screening for inborn errors of metabolism: a systematic review. Health Technol Assess 1997;1: 1-202.

12 Seymour CA, Thomason MJ, Chalmers RA, Addison GM, Bain MD, Cockburn F, Littlejohns P, Lord J, Wilcox AH: Newborn screening for inborn errors of metabolism: a systematic review. Health Technol Assess 1997; 1:1-95.

13 Yoo BK, Grosse SD: Cost-effectiveness of newborn screening for congenital adrenal hyperplasia: a preliminary analysis. National Newborn Screening and Genetic Testing Symposium, Portland, October, 2005.
14 American Academy of Pediatrics, Committee on Genetics: Newborn screening fact sheets. Pediatrics 1996;98:473-501.

15 American College of Medical Genetics: Newborn screening: toward a uniform screening panel and system. Available at: http://mchb.hrsa.gov/screening/. Accessed March 8, 2005.

16 Carroll AE, Downs SM: Comprehensive cost-utility analysis of newborn screening strategies. Pediatrics 2006;117:287-295.

17 Autti-Ramo I, Makela M, Sintonen H, Koskinen $\mathrm{H}$, Laajalahti L, Halila R, Kaariainen $\mathrm{H}$, Lapatto R, Nanto-Salonen K, Pulkki K, Renlund M, Salo M, Tyni T: Expanding screening for rare metabolic disease in the newborn: an analysis of costs, effect and ethical consequences for decision-making in Finland. Acta Paediatr 2005;94:1126-1136.

18 Jaaskelainen J, Voutilainen R: Long-term outcome of classical 21-hydroxylase deficiency: diagnosis, complications and quality of life. Acta Paediatr 2000;89:183-187.

19 Pang S, Clark A: Congenital adrenal hyperplasia due to 21-hydroxylase deficiency: newborn screening and its relationship to the diagnosis and treatment of the disorder. Screening 1993;2:105-139.

20 Murtaza L, Sibert JR, Hughes I, Balfour IC: Congenital adrenal hyperplasia-a clinical and genetic survey. Are we detecting male salt-losers? Arch Dis Child 1980;55:622625.

21 Speiser PW: Improving neonatal screening for congenital adrenal hyperplasia. J Clin Endocrinol Metab 2004;89:3685-3686.

22 Nordenstrom A, Ahmed S, Jones J, Coleman M, Price DA, Clayton PE, Hall CM: Female preponderance in congenital adrenal hyperplasia due to CYP21 deficiency in England: implications for neonatal screening. Horm Res 2005;63:22-28.

23 van der Kamp HJ, Wit JM: Neonatal screening for congenital adrenal hyperplasia. Eur J Endocrinol 2004;151:U71-U75.

24 Perry R, Kecha O, Paquette J, Huot C, Van Vliet G, Deal C: Primary adrenal insufficiency in children: twenty years experience at the Sainte-Justine Hospital, Montreal. J Clin Endocrinol Metab 2005;90:3243-3250.

$\checkmark 25$ Swerdlow AJ, Higgins CD, Brook CG, Dunger DB, Hindmarsh PC, Price DA, Savage MO: Mortality in patients with congenital adrenal hyperplasia: a cohort study. J Pediatr 1998;133:516-520.

26 Virdi NK, Green A: Congenital adrenal hyperplasia in Birmingham: a retrospective analysis (1958-1985). J Inherit Metab Dis 1986;9(suppl 1):152-155.

27 Van Vliet G, Czernichow P: Screening for neonatal endocrinopathies: rationale, methods and results. Semin Neonatol 2004;9:7585 .
28 Werder EA, Siebenmann RE, Knorr-Murset G, Zimmermann A, Sizonenko PC, Theintz P, Girard J, Zachmann M, Prader A: The incidence of congenital adrenal hyperplasia in Switzerland - a survey of patients born in 1960 to 1974 . Helv Paediatr Acta 1980;35:511.

29 Wallace AM, Beastall GH, Cook B, Currie AJ, Ross AM, Kennedy R, Girdwood RW: Neonatal screening for congenital adrenal hyperplasia: a programme based on a novel direct radioimmunoassay for 17-hydroxyprogesterone in blood spots. J Endocrinol 1986;108:299-308.

30 Brosnan PG, Brosnan CA, Kemp SF, Domek DB, Jelley DH, Blackett PR, Riley WJ: Effect of newborn screening for congenital adrenal hyperplasia. Arch Pediatr Adolesc Med 1999; 153:1272-1278.

31 Balsamo A, Cacciari E, Piazzi S, Cassio A, Bozza D, Pirazzoli P, Zappulla F: Congenital adrenal hyperplasia: neonatal mass screening compared with clinical diagnosis only in the Emilia-Romagna region of Italy, 19801995. Pediatrics 1996;98:362-367.

32 Thilen A, Larsson A: Congenital adrenal hyperplasia in Sweden 1969-1986. Prevalence, symptoms and age at diagnosis. Acta Paediatr Scand 1990;79:168-175.

33 Donaldson MD, Thomas PH, Love JG, Murray GD, McNinch AW, Savage DC: Presentation, acute illness, and learning difficulties in salt wasting 21-hydroxylase deficiency. Arch Dis Child 1994;70:214-218.

34 Van der Kamp HJ, Noordam K, Elvers B, Van Baarle M, Otten BJ, Verkerk PH: Newborn screening for congenital adrenal hyperplasia in the Netherlands. Pediatrics 2001;108: 1320-1324.

35 Kovacs J, Votava F, Heinze G, Solyom J, Lebl $J$, Pribilincova $Z$, Frisch $\mathrm{H}$, Battelino $\mathrm{T}$, Waldhauser F; Middle European Workshop on Paediatric Endocrinology-Congenital Adrenal Hyperplasia Study Group: Lessons from 30 years of clinical diagnosis and treatment of congenital adrenal hyperplasia in five middle European countries. J Clin Endocrinol Metab 2001;86:2958-2964.

>36 Torok D, Eckhardt G, Solyom J: Twenty years experience in rapid identification of congenital adrenal hyperplasia in Hungary. Eur J Pediatr 2003;162:844-849.

37 Jaaskelainen J, Levo A, Voutilainen R, Partanen J: Population-wide evaluation of disease manifestation in relation to molecular genotype in steroid 21-hydroxylase (CYP21) deficiency: good correlation in a well defined population. J Clin Endocrinol Metab 1997; 82:3293-3297.

>38 Thilen A, Nordenstrom A, Hagenfeldt L, von Dobeln U, Guthenberg C, Larsson A: Benefits of neonatal screening for congenital adrenal hyperplasia (21-hydroxylase deficiency) in Sweden. Pediatrics 1998;101:E11. 
-39 Therrell BL Jr, Berenbaum SA, Manter-Kapanke V, Simmank J, Korman K, Prentice L, Gonzalez J, Gunn S: Results of screening 1.9 million Texas newborns for 21-hydroxylasedeficient congenital adrenal hyperplasia. Pediatrics 1998;101:583-590.

40 Winter RJ, Klingensmith GJ: Congenital adrenal hyperplasia: mortality experience; in Lee PA, Plotnick L, Kowarski A, Migeon CJ (eds): Congenital Adrenal Hyperplasia. Baltimore, University Park Press, 1977, pp 339344.

41 Toublanc JE, Nivelon JL, Morel Y: Dépistage de l'hyperplasie congénitale des surrénales par déficit en 21-hydroxylase: expérience de l'Association Française pour le Dépistage et la Prévention des Handicaps de l'Enfant. Journées Parisiennes de Pédiatrie. Paris, Flammarion, 1996, pp 81-89.

-42 Votava F, Torok D, Kovacs J, Moslinger D, Baumgartner-Parzer SM, Solyom J, Pribilincova Z, Battelino T, Lebl J, Frisch H, Waldhauser F; Middle European Society for Paediatric Endocrinology - Congenital Adrenal Hyperplasia (MESPE-CAH) Study Group: Estimation of the false-negative rate in newborn screening for congenital adrenal hyperplasia. Eur J Endocrinol 2005;152:869-874.

43 Varness TS, Allen DB, Hoffman GL: Newborn screening for congenital adrenal hyperplasia has reduced sensitivity in girls. J Pediatr 2005;147:493-498.
44 Rohrer TR, Gassmann KF, Pavel ME, Dorr HG: Pitfall of newborn screening for congenital adrenal hyperplasia due to 21-hydroxylase deficiency. Biol Neonate 2003;83: 65-68.

45 Kwon C, Farrell PM: The magnitude and challenge of false positive newborn screening test results. Arch Pediatr Adolesc Med 2000;154:714-718.

46 National Newborn Screening and Genetic Resource Center: National Newborn Screening Information System. Available at: http:// www2.uthscsa.edu/nnsis/. Accessed April 19, 2006.

47 Steigert M, Schoenle EJ, Biason-Lauber A, Torresani T: High reliability of neonatal screening for congenital adrenal hyperplasia in Switzerland. J Clin Endocrinol Metab 2002;87:4106-4110.

48 Kosel S, Burggraf S, Fingerhut R, Dorr HG, Roscher AA, Olgemoller B: Rapid secondtier molecular genetic analysis for congenital adrenal hyperplasia attributable to steroid 21-hydroxylase deficiency. Clin Chem 2005; 51:298-304.

49 Minutti CZ, Lacey JM, Magera MJ, Hahn SH, McCann M, Schulze A, Cheillan D, Dorche C, Chace DH, Lymp JF, Zimmerman D, Rinaldo P, Matern D: Steroid profiling by tandem mass spectrometry improves the positive predictive value of newborn screening for congenital adrenal hyperplasia. J Clin Endocrinol Metab 2004;89:3687-3693.

50 Cutfield WS, Webster D: Newborn screening for congenital adrenal hyperplasia in New Zealand. J Pediatr 1995;126:118-121.
51 Lubani MM, Issa AR, Bushnaq R, al-Saleh QA, Dudin KI, Reavey PC, el-Khalifa MY, Manandhar DS, Abdul Al YK, Ismail EA, et al: Prevalence of congenital adrenal hyperplasia in Kuwait. Eur J Pediatr 1990;149:391392.

52 Sack J, Front H, Kaiserman I, Schreiber M: 21-Hydroxylase deficiency: screening and incidence in Israel. Horm Res 1997;48:115119.

53 Loke KY, Tan IT, Lee WR, Lee YS: Epidemiology of 21-hydroxylase deficiency in Singapore. J Pediatr Endocrinol Metab 2002;15: 397-403.

54 Kaye CI; Committee on Genetics: Newborn screening fact sheets. Pediatrics 2006;118: e934-e963.

55 New MI: An update of congenital adrenal hyperplasia. Ann NY Acad Sci 2004;1038: 14-43.

56 Balsamo A, Cicognani A, Baldazzi L, Barbaro M, Baronio F, Gennari M, Bal M, Cassio A, Kontaxaki K, Cacciari E: CYP21 genotype, adult height, and pubertal development in 55 patients treated for 21-hydroxylase deficiency. J Clin Endocrinol Metab 2003;88:5680-5688.

57 Brosnan CA, Brosnan P, Therrell BL, Slater $\mathrm{CH}$, Swint JM, Annegers JF, Riley WJ: A comparative cost analysis of newborn screening for classic congenital adrenal hyperplasia in Texas. Public Health Rep 1998;113:170178. 